\title{
An assessment of students' learning from term projects
}

\author{
Israel Dunmade \\ Environmental Science Dept., Mount Royal University, Calgary, AB T3E 6K6, Canada
}

Email address:

idunmade@mtroyal.ca, israel_dunmade@yahoo.ca

\section{To cite this article:}

Israel Dunmade. An Assessment of Students' Learning from Term Projects. Science Journal of Education. Vol. 1, No. 5, 2013 , pp. 97-103. doi: $10.11648 /$ j.sjedu.20130105.17

\begin{abstract}
The purpose of this study is to assess students' learning from term projects. A term project is a hands-on assignment that require students to apply ideas, theories, concepts, or principles learned or studied in class to a new situation/real life scenario. Term projects in ENVS 4413 Principles of eco-industrial development are designed to help students connect theory with practice. The aim is to enhance students' learning of the course materials and to give them experiential knowledge of how the course materials are applied in the workplace. A qualitative method was used in the study. Term project reports, midterm exam papers and final exam papers submitted by students were the sources of data used in assessing students' learning from the term project. Term project reports and exam papers submitted by students were assessed in terms of solutions suggested for the problem situation, eco-industrial theory applied, the relevance of the theory applied, and the degree of effectiveness of the student in using the theory to profer solution to the problem. Data analysis showed that $87.5 \%$ of students in the class accurately diagnosed the problem, used appropriate eco-industrial theory in providing suitable solutions to solving the encountered problems and was highly effective in using the appropriate theory to solving the problem, $12.5 \%$ did not use the theory effectively. Findings from the students' performances revealed that term project aids students' learning and enables them to connect theory with practice. This assures the compliance of the Bachelor of Applied Environmental Science (BAES) degree program with the original program design and facilitates the success of Mount Royal University's BAES degree students.
\end{abstract}

Keywords: Applied Degree Program, Collaborative Project-Based Learning, Connecting Theory with Practice, Environmental Education, Principles of Eco-Industrial Development, Problem-Based Learning, Term Project

\section{Introduction}

Professional education in disciplines like medicine, engineering, law, and environment is aimed at preparing students for proficiency in their specific discipline areas after graduation. However, many graduates of professional degree programmes only know theories on what should be done without a grasp of how it should be done. Identification of this deficiency has resulted in innovative changes to a number of professional degree programmes' implementation processes. One of such innovations is the development of problem-based and project-based learning pedagogies.

This study evaluates the effectiveness of a hybridized problem-based and project-based learning pedagogy in an environmental degree programme. It involves an assessment of the effectiveness of term project in helping applied environmental science degree students to connect theory with practice.

A term project is a hands-on assignment that require students to apply ideas, theories, concepts, or principles learned or studied in class to a new situation/real life scenario. It is a form of project based learning method [1, 2]. It involves students in investigative activities, problem-solving, and decision-making. It also gives students the opportunity to work relatively autonomously over an extended period of time, culminating in realistic products and presentations. Term projects include authentic content, cooperative learning, reflection, and incorporation of skills necessary to solving real problems in workplace environment. Moreover, term projects have explicit goals and it is teacher facilitated but not directed. They are designed to make a connection between activities and the underlying conceptual knowledge that one intend to foster [2-5]. Employment of term project instrument in environmental education became necessary in view of some changes in post secondary education policy in Alberta some years ago.

A number of the changes in Alberta's post-secondary education policy in the 1990s were made in order to satisfy the need for more middle level manpower especially in 
Northern Alberta. The need for more environmental professionals came as a result of an ever increasing environmental awareness all over the world. This includes the awareness of the enormity of our resource consumption, environmental releases, and the potential consequences. The consciousness of the implications of resource consumption and of the environmental releases trend on human and industrial ecosystem welfare both in the near and distant future has led to increased advocacy for environmental stewardship. As a result, proactive manufacturing industries, government agencies and other stakeholders are taking steps to reduce our ecological footprints. However, the skills and expertise of environmental scientists are needed in order to adequately address environmental issues resulting from our economic activities. The increasing expansion of our economic activities in Alberta necessitates the recruitment of more and more environmental scientists. Environmental scientists are needed by governmental agencies to formulate, monitor and enforce environmental policies. They are also needed in the oil and gas industry and other sectors of the economy to help in developing innovative approaches that reduce the ecological footprints of our industrial activities. Sufficient number of environmental scientists needed to meet these demands is usually in short supply. Consequently, applied environmental degree program, like other applied degree programs in Alberta, was developed to address the training needs. The four-year applied environmental degree program at Mount Royal University consists of six semesters of in class studies and eight months of direct field studies. The applied degree program was designed to provide a good balance of theory, applied coursework, arts and science courses, and hands-on experience. The principles of eco-industrial development course (EID) is a fourth year capstone applied coursework designed to facilitate students ability to not only be able to connect theories learned in the course but in other courses taken by students in the program with their real world applications [3].

\subsection{Theory and Its Uses}

Before we can talk of application of theory we need to understand the purpose of theory. It is also important to know what it means to connect theory with practice, what is involved and how it can be realized. In [6], theory was defined as "a scheme of interrelated concepts which are empirically verifiable." He also articulated four uses of theory. According to Gitterman [6], theory:

- "Provides a frame of references which simultaneously focuses and circumscribes our observations",

- "Provides us with a classification scheme to organize our observations", thereby fixes our attention and keeps us from wandering all over the place",

- "Allows us to conceptualize and consolidate our observations, and through the "short-cut" of a concept we are able to describe and to discuss phenomena parsimoniously", and

"Enables us to recognize and predict behaviour because it has identified observable patterns, that is, empirical uniformities and ascribed meaning to them".

\subsection{Students' Ability to Connect Theory with Practice Versus Students' Learning}

So, theory is a platform or basis for practical applications. Connecting theory with practice can be explained from two perspectives. One can explain it: (i) from theory to practice or (ii) from linking practice to theory. In this study connecting theory with practice was looked at from the second perspective: connecting theory with practice means being able to diagnose a given problem situation, recollect previously learned theory or studies carried out for addressing similar problem and then making appropriate draw of suitable concept(s) out of many concepts learned to address the real life problem.

Teaching students how to connect theory with practice is necessary because many of the post-secondary education curriculums "tend to communicate a fragmented view of knowledge, both in coursework and in field experiences" [7]. Teaching students how to employ theory with appropriate application has many benefits. One of the benefits is that it will enable them to be able to "hit the ground running" as soon as they start their professional career. It will also reduce the length of post-graduation training required before their employers can commit professional duties to their hands. In addition, it will reduce training cost to the employer. Moreover, it will increase their overall productivity in the workplace. It is believed that the extent to which a student can apply relevant theories learned in solving real-world problems is a good indication of the depth of his/her learning the subject matter.

\subsection{Students' Learning to Connecting Theory with Practice}

Teaching students to identify and connect appropriate theory with the right application is challenging. In recognizing this challenge, Gittermann [6] said "a natural or easy connection does not exist between theory and practice" However there are a number of steps that could be taken to overcome the challenges in order to achieve the desired goal. He then provided an insight on how the challenge could be overcome. He said "the very act of making connections between theory and practice requires the student to face the task of bridging the abstract and real worlds". He also said that "teaching students to connect theory and practice requires helping them to break through theoretical and personal boundaries, cultivating their natural curiosity and spontaneity". Furthermore, He opined that it requires allowing "the student to define problems interactionally rather than individually, and with the instructor, risk and explore that which is less known, less developed, less structured and less certain".

\subsection{Learning by Bridging the Abstract and Real Worlds}


How then can teachers help students to break through theoretical and personal boundaries, cultivate their natural curiosity, and bridge the abstract and real worlds? What are the activities and approaches that facilitates students' ability to connect theory with practice? Different scholars have tried and advocated varied strategies for developing students as evolving professionals. In [8], it was explained that the gap between theory and practice can be bridged by providing students "with multiple opportunities to apply what they have learned in meaningful contexts". They also supported the view that "site-based experience provides students (i.e. "professionals in the making") with more opportunities to successfully apply what they are learning within the context of the classroom." It is believed that such multiple opportunities for students to apply what they have learned in meaningful context can be provided by designing and implementing an assemblage of activities that take place both in the class and at some sites where they are likely to work as professionals. According to American Association for the Advancement of Science [9], such activities should be "tangible and directly accessible to their senses-visual, auditory, tactile, and kinesthetic." "With experience in such activities, students would grow in their ability to understand abstract concepts, manipulate symbols, reason logically, and generalize." This was supported in [10], where it was opined that "optimal learning occur for students as evolving professionals when they are provided with experiences to translate the theory and practice gained into tangible outcomes for their clients."

Term projects in the principles of eco-industrial development course at Mount Royal University were designed to achieve the goal of bridging the gap between theory and practice by giving students opportunities to apply what they learned in class to solve corporate real-life problems.

\subsection{Evaluation of Students' Competence in Connecting Theory with Practice}

Several studies in the last two decades indicated that students learn better in the context of a compelling problem and through experience. They also learn through making cognitive connections, social connections, and experiential connections better than through only dissemination in the lecture method [11]. Because students do not learn in the same way and at the same rate, it becomes necessary to evaluate the level of effectiveness of term project in helping students to connect theory with practice. It becomes necessary to assess the extent to which this new hybrid pedagogy of problem-based and project-based learning affect students' competence in solving real-world problem. Although the shift in education from teaching to learner centred pedagogies is a welcome change, many scholars have recognized the need for constructive alignment between instruction, learning and assessment. For instance, Baartman et al [12] were of the opinion that instruction, learning, and assessment should be based on the same underlying principles of competence based learning. They reported a growing call for the development of assessment methods that can adequately determine competence acquisition. Baartman and other researchers believe that innovation of assessment might even be the cornerstone of success for the implementation of competence-based education. They reported that studies have shown that no greater impulse for learning exists than assessment and that a strong relationship exists between learning and assessment, implying that what is assessed strongly influences what is learned.

To this end, competences of students in connecting theory with practice are assessed by evaluating how they demonstrate it in their term project reports and how they answer real-world scenario based questions they are given in their mid-term and final exams.

\section{Context}

Mount Royal University is a mid-size undergraduate university in Western Canada. It offers a variety of bachelor degrees in Arts, Business, Education, Nursing, and Science. The University offers six applied degrees of which Environmental Science is one of them. ENVS 4413 Principles of eco-industrial development course is one of the capstone courses in the 4 year applied environmental science degree program at Mount Royal University. It was designed to enable students to harmonize and apply the knowledge they acquired in various courses in a real life situation. Eco-industrial development (EID) is a win-win preventive approach to environmental protection. An eco-industrial development could either involve the development of an eco-industrial park or an eco-industrial network. It could also involve the conversion of an existing industrial park or a brownfield to an eco-industrial park or network.

An eco-industrial park (EIP) is a group of businesses that are situated in the same geographical location for the purpose of sharing mutual benefits. In an EIP, wastes or by-products of one company serves as input for another company that is on the same location. Businesses in such park are pre-selected to ensure the existence or possibility of synergetic relationship between them. The relationship is usually formalized at the onset of the co-location.

An eco-industrial network (EIN) is also a group of businesses with or without formal agreement that they will take each other's wastes for conversion into value-added products, thereby eliminating the need to send those wastes to a landfill, an incinerator or a wastewater treatment plant. Such collaboration(s) could also be facilitated by a third party. Businesses involved may be at the same location or they may be at different geographical locations. However, they are usually not far apart. They are often in the same region. This approach to implementing EID is also called virtual eco-industrial park (Virtual EIP).

An Industrial park is a group of businesses co-located on the same piece of land. Industrial parks are designed to 
enable businesses at the location to share the same infrastructure but they may have or may not have any relationship with one another. Brownfield is a piece of property that has been abandoned or under-utilized due to contamination or perceived contamination. This kind of property can be converted to either an eco-industrial park or an eco-industrial network.

Eco-industrial Park (EIP) is the most preferred of the three ways of implementing EID. This is because it has the highest environmental benefits. However, eco-industrial network (EIN) is the easiest to implement because of its lowest financial requirement.

By taking this course, students that graduate from the applied environmental degree program were expected to apply the knowledge acquired in the course and in the program to help their employers and the community at large to reduce the ecological footprint of our economic activities.

\subsection{Term Project}

The course structure is a mixture of lectures, a group assignment, a mid-term exam, a term project, and the final exam. The mixture was aimed at giving students experiential learning that would bridge the gap between theory and practice. Various theories of eco-industrial development were taught in a two hour lectures per week for 10 weeks in the semester. The group assignment part of the course involved dividing students into groups of three students and assigning each group to study an existing eco-industrial parks and eco-industrial networks. Each group then presents their findings to the class at the end of the three weeks period. The term project component of ENVS 4413 course itself consisted of five activity-based reflective journals, an industrial visit, group discussions, final report writing, and a group presentation [3].

This study was approved by Mount Royal University Human Resources Ethics Board. Participants in the study were final year bachelor of applied environmental science degree students. 19 out of the 23 students that enrolled in the course participated in the study. Written consent from students to analyze students' reflective writing, end-of-semester survey, term project reports, and exam answer scripts were obtained on the first day of the class. The required data was collected in the Fall 2010.

\section{Methodology}

Varieties of data collection instruments and course activities were designed to assess students' learning from term projects and to evaluate term projects' effectiveness in helping students to connect theory with practice.

The two course assignments analyzed in this study were term project reports and examination scripts submitted by students.

\subsection{Term Project Reports}

In their professional careers students would definitely have to write technical reports on whatever project they are involved in. This informed the reason for requiring each student that takes this course to write a report on their group term project. They were given report framework showing what are expected in their term project report. Each student's term project report was analyzed for: (i) content, (ii) relevance, and (iii) depth of coverage in relation to what was specified in the report framework given them as part of the course outline on the first day of the class. Specifically, the report framework given to them required that they should identify eco-industrial problems of the company they worked with, develop an eco-industrial network model for solving the problem, explain how the implementation of the model will result in solution to the problems, eco-industrial theories they applied in solving the problems, what they learned from their experience, and how they can apply the knowledge gained in other real life problems.

\subsubsection{Evaluation of Students' Learning from Term Project Reports}

Students' projects were evaluated on the extent to which they include the following criteria that reflect effective EIN model were incorporated into their models and explained in their reports. A good eco-industrial network (EIN) model would identify resource needs and environmental emissions from each of the participating organizations. It will also assess the quantity and quality of resources needed by each of the participants. Furthermore, a good EIN model will also determine the type, the form, the quantity, and quality of the emissions produced by the participants. Reusability of the emissions produced by the participants would then be assessed by examining which company can use which waste. In addition, the assessment will attempt to match type, quantity and quality of each waste stream with the demands by the participants. Proximity consideration is an important parameter in determining the ecological and economic viability of the project. Rubrics were developed to evaluate the degree of closeness of students' performance to these expectations. Appropriate points were assigned to each section and parameters expected in the reports.

\subsection{Students' Examination Questions}

In the exam, students were given two situation based industrial problems that they would possibly encounter in their career. The aim was to assess their competence in solving the problems using appropriate eco-industrial theory they learned in the course. Another reason for posing such questions was to assess their levels of effectiveness in applying such theory to solve the problems. Students' answers to each of the exam question were analyzed in relation to accuracy of problem diagnosis, appropriateness in the choice of relevant theory, and correctness and depth of coverage of how the problems would be addressed. 


\subsubsection{Assessment of Students' Competence to Connect Theory with Practice in Solving Real-World Problems Presented in the Final Exam}

It is a popular saying that exam is not the most accurate approach to evaluating students' knowledge and ability. Reasons for this conclusion include "exam fever" or fret that makes some students perform below their capability. Another reason includes the nature of the exam, and how well the exam questions are framed. A student may not have accurate understanding of what is being asked if the questions are poorly framed. However, well designed exams can provide a fair reflection of students understanding of the subject, of students' ability, and competence. In assessing students' learning from term project and their competence in connecting theory with practice, the following application questions were asked in their exams:

Q1: There are three towns A, B and C. Each of them started an eco-industrial park in the year 2000. (i) Apart from the intention to start an EIP, town A couldn't proceed further in realizing the EIP project. (ii) Town B has put transport, water and electrical infrastructures in place, their EIP project halted just at the point of constructing the buildings. (iii) Town C's EIP is operating but it is not breaking even

a) For each of the three EIP projects, list what could possibly be the problem(s)/or causes of their problems and explain why you think those are their problems or causes of their problem?

b. How will you address each of the listed problems or the causes of the problems and why will you address it that way?

c. What could be the potential problems of implementing your recommended solutions and why?

d. How will you avoid, minimize or solve the potential problems of implementing your recommended solutions?

Q2: Town X has just heard of potential benefits of having an Eco-Industrial Park (EIP) in the town. Assuming they don't know anything about EIP and they hired you as their Eco-Industrial Park Development Consultant:

a. describe the process you will take them through from the scratch (i.e. the beginning) to the point of operating their EIP and including the process of operating the EIP.

b. What are the possible problems you may encounter in taking them through the process you described in $2 \mathrm{a}$ and why would you encounter each of the problems?

c. How will you avoid, minimize or solve each of your problems that you listed in $2 \mathrm{~b}$, why will you address those problems that way and/or why do you think taking those steps will avoid/minimize/solve the problems?

d. Explain why they may have each of the problems and risks you listed

e. If you are the mayor of Town X, explain how you will avoid, minimize or solve each of the problems and risks you highlighted

In evaluating students' competence in identifying possible causes of the problems and finding solutions to the problems, their answers were assessed in relation to the marking schemes prepared for the questions. The marking scheme listed known possible causes of the problems and solutions to each problem. Provisions were also made for credible answers outside the listed ones. Points were assigned to each question according to the depth of knowledge required to answer them. The number of points given to each answer provided by students were based on the level of competence displayed in answering the questions.

\section{Findings and Discussion}

\subsection{Evaluation results of Students' Competence from Term Project Reports}

Figure 1 and 2 show samples of eco-industrial network models developed by the students while Table 1 shows a sample of cost benefit analysis of the eco-industrial network models proposed by a group of students. They were extracted from students' term project reports.

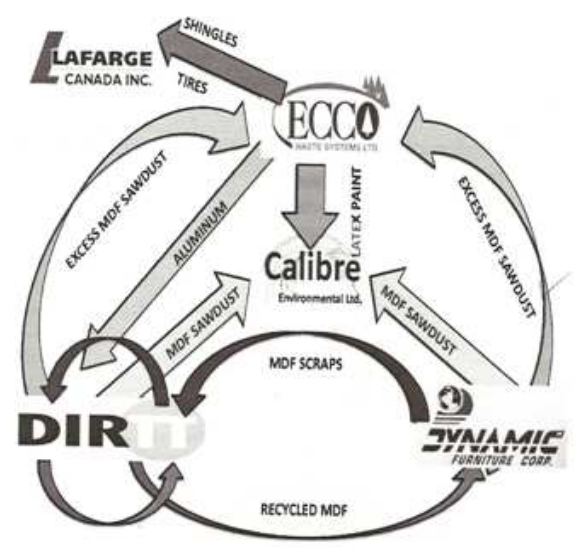

Figure 1. A sample of Eco-industrial network model developed by a group of students (Group 1)

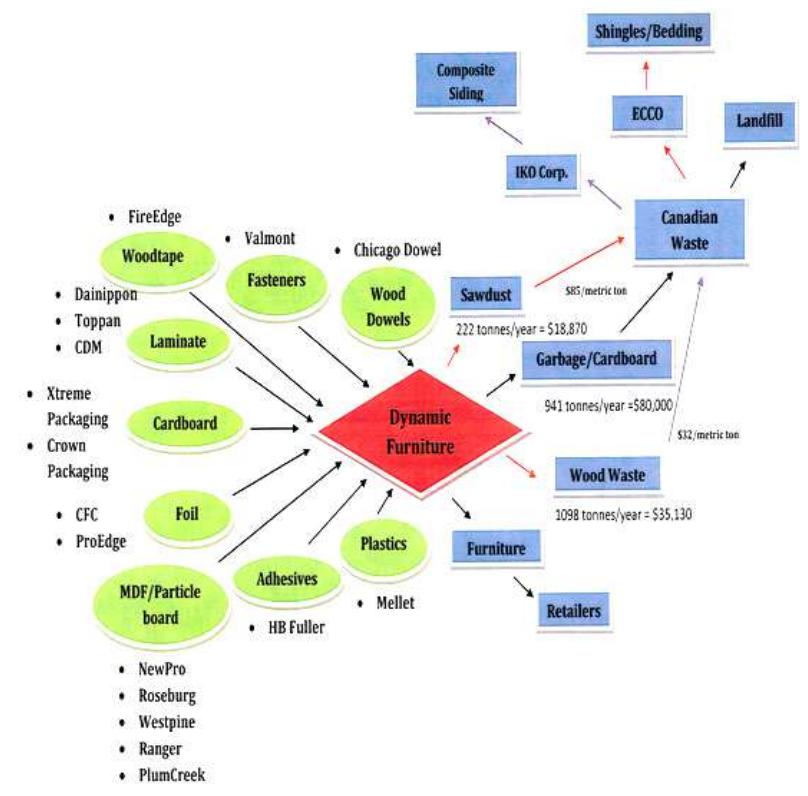

Figure 2. A second sample of eco-industrial network models developed by a group of students (Group 2) 
There were trial conceptual eco-industrial networks developed in the class in the course of the semester. An assessment of eco-industrial network models developed by each group of students in their term projects showed that majority of the students developed well-articulated eco-industrial network (EIN) models. Most of the groups also did thorough cost benefit analyses. Eco-industrial network models developed by each group of students, their explanation of how they diagnosed the nature of problems, how they developed the models for finding solutions to the problems identified, and theories applied were evaluated. The evaluation compared what they did in relation to expectations specified in the rubrics.

Table 1. A sample of cost benefit analysis of a proposed EIN model

Disposal Costs

\begin{tabular}{|c|c|c|c|c|c|c|c|}
\hline \multicolumn{4}{|c|}{ Current Practice } & \multicolumn{4}{|l|}{ Network } \\
\hline Material & $\begin{array}{l}\text { Unit Cost } \\
\text { (per tonne) }\end{array}$ & $\begin{array}{l}\text { Amount Disposed } \\
\text { Annually (tonnes) }\end{array}$ & $\begin{array}{l}\text { Annual Cost } \\
\text { (\$) }\end{array}$ & Material & $\begin{array}{l}\text { Unit Cost (per } \\
\text { tonne) }\end{array}$ & $\begin{array}{l}\text { Amount Disposed } \\
\text { Annually (tonnes) }\end{array}$ & $\begin{array}{l}\text { Annual Cost } \\
\text { (\$) }\end{array}$ \\
\hline Wood & 32 & 1098 & 35136 & Wood & 20 & 1098 & 21960 \\
\hline Garbage & 85 & 800 & 68000 & Garbage & 85 & 800 & 68000 \\
\hline Sawdust & 85 & 222 & 18870 & Sawdust & 0 & 222 & 0 \\
\hline Cardboard & 85 & 141 & 11985 & Cardboard & 0 & 141 & 0 \\
\hline Total & & 2261 & 133991 & Total & & 2261 & 89960 \\
\hline
\end{tabular}

Cost Savings $=\$ 44031$

Evaluation of students' performances in their term projects revealed that majority of students demonstrated fairly high degree of competence in connecting theory with practice. Results of the evaluations showed an average competence level B+ (i.e. 77 - 79\%). Since skills on how to connect theory with practice in developing an eco-industrial network model was taught through the term project activities, it can be inferred that term projects have helped students in developing skills to connect theory with practice.

\subsection{Evaluation Results of Students' Competence in Connect Theory with Practice from their Answers to Real-World Problems Presented in their Final Exam}

Table 2 shows students' competences in answering each of the two questions given them in the final exam. They were based on the evaluation criteria explained in section 3.2.1.

Table 2. Students' performances in answering each of the two questions

\begin{tabular}{lll}
\hline Grade & $\begin{array}{l}\text { \% of Students with the } \\
\text { score on Q1 }\end{array}$ & $\begin{array}{l}\text { \% of Students with the } \\
\text { score on Q2 }\end{array}$ \\
\hline A & $12.5 \%$ & \\
A- & $12.5 \%$ & \\
B+ & $37.5 \%$ & $25 \%$ \\
B & & $50 \%$ \\
B- & $25 \%$ & $25 \%$ \\
D & $12.5 \%$ & \\
\hline
\end{tabular}

The following is a typical answer to question Q1.

"The problem of town A may be due to its inability to gain community support or inability to attract suitable tenants which could have been as a consequence of not providing sufficient incentives and motivations. Town B appears to have made a good design planning but the problem may be unanticipated or ballooned costs and as a result did not have adequate funding for the implementation. Town $\mathrm{C}$ may not have good market access or responsive market. This may be as a result of poor planning especially in the area of correctly identifying assets and interests in the community. Another reason for the failure could be due to their not providing the right amenities that could attract customers, defective marketing strategies, or high cost of waste management.

To address the lack of community support problem for town A's EIP project, I will take a critical look at the community characteristics, how these characteristics can be capitalized on and used to gain community support, and provide compelling reasons for the community and industries to become involved. As well, I would identify the needs and desires of the community through a baseline study and incorporate them into the project implementation program. I would solve the problem of attracting tenants by identifying and attracting viable companies. This would be done by developing industry/supplier tree for the project. In addition, I will look for import substitution possibility by identifying what is brought in to the town and seek available opportunities for local production. Furthermore, I will look for opportunity to absorb lost resources by identifying companies that could use wastes generated by each other as raw materials.

The cost and funding problems of town B's project will be solved by detailed accounting for the cost of specific items in the project and by making sure that proper funding is available for the project before initiating the project implementation. I will also solve the funding problem by setting up a foundation or by applying for funding through conventional means (loan), or applying for private or 
government grants.

To address the town C's market access problem, I will review their marketing plan, and identify other potential targets and their needs. I will then develop effective marketing strategies to attract potential tenants (companies) and link them with customers that would patronize them. The strategies that I would employ include direct mailing, web-based marketing, and marketing the town's EIP to stakeholders by organizing open house, workshops and seminars." (Student M)

An evaluation of students' competence in connecting theory with practice and in demonstrating their learning was reflected in their answers to the two questions and was also indicated in their scores. Results of the evaluation showed that $87.5 \%$ of the students performed well in Q1 and only $12.5 \%$ did poorly in Q1. In addition, all the students performed well in Q2. The average score by students in Q1 is 78.5\% (B grade) and their average score in Q2 is $76.8 \%$ (B grade). These showed that majority of the students used various eco-industrial development principles effectively in solving the problems. Majority also demonstrated deep learning of eco-industrial development concepts and ability to apply the concepts learned. Since skills required to answer these questions were taught in the class lecture and term project exercises that gave them examples. Their responses demonstrated competence in being able to apply the knowledge to novel real world applications.

\section{Conclusion}

Findings by this study revealed that term project helped students learning of the principles of eco-industrial development course. It also helped students in connecting theory with practice by enabling students to see how EIPs develop and function in the real world. In addition, results of the evaluation of students' performance in the term project reports and in their exams confirmed AAAS findings that experience makes students to grow in their ability to understand abstract concepts, reason logically, and generalize. It also showed that site-based experience provides students with more opportunities to successfully apply what they are learning within the context of the classroom. Further studies and analyses would be necessary to monitor changes in students learning from term projects as the project progresses in the semester. Future studies would also be directed at understanding the role of term project structure on students' learning and on their ability to connect theory with practice.

\section{Acknowledgements}

The author would like to acknowledge the opportunity and support given by Institute of Scholarship and Learning and Faculty of Teaching and Learning at Mount Royal University, Calgary to undertake this study. He would also like to thank all students that participated in the study.

\section{References}

[1] L. Helle, P. Tynjälä and E. Olkinuora, Project-Based Learning in Post-Secondary Education: Theory, Practice and Rubber Sling Shots, Higher Education, Vol. 51, No. 2, 287-314.

[2] J.W. Thomas, "A review of research on project-based learning," Online available from http://www.autodesk.com/foundation.

[3] I. Dunmade, Effectiveness of Term Projects in Helping Students to Connect Theory with Practice: an Evaluation of Students' Perspectives, Education Journal, Vol. 2, No. 1, 1-6.

[4] L. Andresen, D. Boud and R. Cohen, Experienced-based learning, In: G, Foley. (Ed). Understanding adult education and training, 2nd ed. Sydney: Allen \& Unwin, 2000, 225-239.

[5] M. Daniels and L. Asplund, Full Scale Industrial Project Work: a one semester course, In the proceedings of the $29^{\text {th }}$ ASEE/IEEE Frontiers in Education Conference, November 10 - 13, 1999 San Juan, Puerto Rico.

[6] A. Gitterman, Teaching students to connect theory and practice, Social Works with Groups, Vol. 11, No. 1/2, 33-41.

[7] F. A. Korthagen and J. P. Kessels, Linking_theory_and_practice: Changing the pedagogy of teacher education, Educational Researcher, Vol. 28, No. 4, 4-17.

[8] D.H. Allsopp, D. DeMarie, P. Alvarez-McHatton and E. Donne, Bridging the Gap between Theory and Practice: Connecting Courses with Field Experiences, Teacher Education Quarterly, Winter 2006, 19-35.

[9] American Association for the Advancement of Science (AAAS), Science for all Americans: Project 2061. New York: Oxford University Press, 1990.

[10] Tsang, A.K., In-class Reflective Group Discussion as a Strategy for the Development of Students as Evolving Professionals, International Journal for the Scholarship of Teaching and Learning, Vol. 5, No. 1, 1-20, Online available from http://www.georgiasouthern.edu/ijsotl

[11] C.H. Major and B. Palmer, "Assessing the effectiveness of problem-based learning in higher education: lessons from the literature, Academic Exchange Quarterly," vol. 5(1), Spring 2001. Online available from http://www.rapidintellect.com/AEQweb/mop4spr01.htm

[12] L.K.J. Baartman, T.J. Bastiaens, P.A. Kirschner and C.P.M. Van der Vleuten, "Evaluation assessment quality in competence-based education: A qualitative comparison of two frameworks," Educational Research Review, Vol. 2, 114-129.

[13] J.E. Mills and D.F. Treagust, "Engineering education - is problem-based or project-based learning the answer?" Australasian journal of engineering education" 